NBER WORKING PAPER SERIES

\title{
MONETARIST RULES IN THE LIGHT OF
} RECENT EXPERIENCE

Bennett T. McCallum

Working Paper No. 1277

\section{NATIONAL BUREAU OF ECONOMIC RESEARCH 1050 Massachusetts Avenue \\ Cambridge, MA 02138 \\ February 1984}

Prepared for AEA Session "Monetarism: Lessons From the Post-1979 Experiment," December 28, 1983. The research reported here is part of the NBER's research program in Financial Markets and Monetary Economics. Any opinions expressed are those of the author and not those of the National Bureau of Economic Research. 


\section{Monetarist Rules in the Light of}

Recent Experience

\section{ABSTRACT}

Recent experience does not include a "monetarist experiment," as some have argued, but may slightly reinforce preexisting reasons for doubting that the best way of formulating monetarist policy prescriptions is in the form of a constant growth rule for the money stock. A more desirable rule would pertain to the monetary base, which is much more directly under Fed control. While a constant base growth rule might provide good macroeconomic performance, better results should be obtainable from a rule that at regular intervals adjusts the base growth rate upward or downward depending on whether nominal GNP is below or above a target path that specifies constant, non-inflationary growth for that variable. This type of rule is activist, to an extent, but is non-discretionary. The implied absence of policy-making flexibility is desirable for reasons explained in the literature on dynamic inconsistency.

Bennett T. McCallum

Graduate School of

Industrial Administration Carnegie-Mellon University

Pittsburgh, PA 15213

(412) $578-2347$ 
MONETARIST RULES IN THE LIGHT OF

RECENT EXPERIENCE

Bennett T. McCallum*

The title of this session, like a host of recent writings by critics of monetarism, suggests that the period from late 1979 to mid 1982 witnessed a significant "monetarist experiment," i.e., that U.S. monetary policy during that period conformed to monetarist prescriptions. For a number of reasons, however, that suggestion is clearly untenable. Among these are the following: growth rates of monetary aggregates fluctuated widely on a month-to-month or quarter-to-quarter basis; the Fed's operating procedures were more poorly designed for money stock control than those in place prior to October, $1979 ;^{1}$ and discretionary responses to current cyclical conditions were never foresworn. In addition, the growth rate of the (M1) money stock was only slightly lower than that of the previous decade and was higher than that of the previous 20 years. ${ }^{2}$ It is true that the Fed demonstrated considerable resolve in reducing $M 1$ growth rates from the values of 1977-78 even though this required a spell of unusually high interest rates, and the operating procedures announced in October 1979 were politically helpful in disclaiming responsibility for these unpopular rates. But such steps hardly constitute an embrace of monetarism--an opinion shared, it might be added, by officials of the Fed as well as leading proponents of monetarism. 3

Consequentiy, any argument of the form "we tried monetarism and it produced undesirable results" seems to me unworthy of discussion. But that conclusion does not eliminate the 
possibility that the time period since 1979 has produced new evidence relevant to a reasoned consideration of the desirability of monetarist prescriptions. It is, in other words, conceivable that the new data points generated during that period were so highly informative about the nature of the economy that opinions concerning the merits of monetarist prescriptions could reasonably have been altered. Let us then continue the discussion from that perspective.

\section{NEW EVIDENCE}

Contemplating the developments of 1979-82, one is led to the conclusion that the main new information relevant to monetarism does not pertain to the behavior of macroeconomic variables or their inter-relationships. Much of the discusion has, admittedly, emphasized the unusually high interest rates (nominal and ex post real) of 1980-81, the severe unemployment of 1982, the rapid decline in inflation between 1981 and 1982 , and the sharp fall in M1 velocity during 1982. But none of these facts is incompatible with the basic hypotheses about the economy that are essential to a monetarist position, namely, that money stock movements have strong effects on nominal GNP and that there is no permanent tradeoff between unemployment and inflation. 4 Nor do these facts serve to discredit--indeed, quite the contrary!--the monetarist presumption that no one possesses a ieliable structural model of the economy. Instead, the new developments that deserve attention are those pertaining to technological innovation and regulatory change in the payments industry, prominent examples of 
which include the introduction of NOW and sweep accounts, the growth of money market mutual funds, and the widespread use of repurchase agreements. These developments have, as is well-known, led to redefinitions of traditional monetary aggregates such as $M 1$ and $M 2$ and have weakened the correspondence of the former to the concept of the medium of exchange. As a consequence, the developments have engendered a widespread belief that the economy's demand function for any operationally-defined monetary aggregate has been subject to significant shifts and will continue to shift in an unpredictable fashion in the future.

In saying this, I do not mean to deny that these developments have in large part been a response to prevailing regulations and policy. Nor do I mean to express agreement with antimonetarist observers who justify each departure from announced monetary targets with a claim that money demand has shifted, or those who believe that all tangible media of exchange will soon disappear as modern economies adopt accounting systems of exchange. Nor do I wish to suggest that technical progress in the payments industry is something new, which it surely is not. But I nevertheless believe that recent experiences have served to reinforce preexisting reasons for doubting that the best way of expressing monetarist prescriptions is in the form of a constant growth rate rule for the money stock. While the latter-whether measured as M1 or M2--could certainly be made more controllable by the Fed, wide-ranging institutional changes such as those recommended in Milton Friedman's Program for Monetary Stability (1960) would be required for truly tight control. 5 Consequently, it will probably 
continue to be the case that the money stock, which is not an ultimate goal variable, is also not a directly-manipulable monetary irstrument.

II. A REVISED MONETARIST RULE

Because of this intermediate status of the money stock--identifiable as neither instrument nor goal variable--its role is undesirably ambiguous. It is thus not surprising that money. stock "targeting" as practiced by the Fed has been characterized by ambiguity, with departures from target values sometimes treated as something to be eliminated but often as mere bits of information requiring no response. It would be better, it would appear, to have a rule that specifies behavior of the monetary base, or stock of high-powered money, which is directly enough under Fed control to be treated as a bona fide instrument. 6 With observations on the base obtainable from Fed and Treasury balance sheets, its magnitudes could be monitored almost continuously and no significant departures from specified target paths would ever need to occur.

It will be objected that the velocity of the base relative to GNP will again be changing irregularly in the future so that a constant growth rate for the base would be undesirable. But there is nothing in the concept of a rule that requires the growth rate to be constant. Personally, I suspect that constant base growth at 1\% per year over the next decade would yield satisfactory macroeconomic performance. But still better performance should be provided by a rule that periodically adjusts the base growth rate 
in response to past movements in some nominal target variable, with nominal GNP an attractive candidate. Thus in my opinion a desirable monetarist rule would adjust the base growth rate each month or quarter, increasing the rate if nominal GNP is below its target path and vice versa. This target path, in turn, should specify nominal GNP growth of about $3 \%$ per year, a figure consistent with near-zero inflation.

There are three distinct ways, deserving of explicit mention, in which macroeconomic performance could benefit from an adjustable growth rate rule as compared with one of the constantgrowth rate (CGR) type. First, the adjustable scheme could correct for any tendency of base velocity growth to change secularly as the pace of technological innovation increases or decreases. Second, there would be stronger countercyclical effects on aggregate demand and these would be of an automatic type. 7 Third, the adjustments would counteract the tendency --discussed in McCallum (1981)-- of CGR rules plus fixed tax schedules to generate dynamic instability in the stock of government debt.

I am confident that both monetarists and anti-monetarists will object to this proposal, partly for substantive reasons and partly because I have termed it "monetarist." Taking the last objection first, the label is warranted because the proposed rule is entirely non-discretionary and is expressed exclusively in terms of nominal magnitudes. Substantively, the only apparent drawback from a monetarist perspective is that the adjustable base growth rate lacks the popular appeal of an absolutely constant 
value. Wnile an adjustable path would be sightly harder to monitor than a constant path if everything else were the same, having a path expressed in terms of an instrument variable should provide greater operational content and improved monitoring possibilities in comparison with a constant growth path for a variable that can only be controlled indirectly.

The substantive objections from non-monetarists will be different, of course, and will presumably focus on the non-discretionary aspect of the proposal. In this regard, it is important to recognize that while the rule is non-discretionary, it is not non-activist. That is, the rule specifies instrument settings for the base growth rate that are contingent on the state of the economy--nominal GNP relative to its target path. It is less activist than a rule that (for example). prescribes higherthan-average nominal GNP growth when unemployment is above average, but it is activist nonetheless. An important reason for not attempting the more ambitious type of rule is the absence of a reliable model of the economy. If such a model were available, it vould make no sense to use an intermediate target variable like nominal GNP, rather than focussing directly on ultimate goals (B. Friedman, 1975).

\section{RULES vS. DISCRETION}

There remains to be discussed why the Fed shouid adopt any rule at all, rather than proceeding in a discretionary manner, as the latter would permit the same month-to-month base growth values as the rule would dictate but would also provide the virtue of 
flexibility. The answer is that, given the nature of the U.S. economy, flexibility is not a virtue; the absence of flexibility could lead to superior performance in terms of unemploymentinflation combinations. To make this argument as simply as possible, I will utilize an analogy. 8 Imagine parents confronted with an instance of misbehavior by their child, whose welfare is uppermost in their minds. Shall they punish the child for the misbehavior, thereby inflicting disutility on themselves as well as the child? or shall they refrain from punishment in this particular case, while promising punishment for all future instances of misbehavior? From the viewpoint of the moment in time when this decision is being faced, it is clearly optimal to select the second of these options. But of course the same choice will turn out to be optimal after the next instance of misbehavior, and so on, so the resulting steady state is one in which the parents never punish the child, whose behavior accordingly conforms to a regime in which there is no need ever to fear punishment.

In an economy with widespread nominal contracting, the problem faced each "year" is similar to that of parents confronted with an instance of misbehavior. The options are to impose monetary stringency, with resulting disutility for most parties, or to refrain from stringency this year while promising stringency in all future years. But with decision-making flexibility, the same choice will be made in future years when the intervening year's misbehavior becomes a thing of the past. Thus stringency tends to be imposed rarely, yet--since there is no permanent 
stimulus to employment from monetary leniency--there is no additional employment to compensate for the additional inflation that results from monetary leniency.

Some parents, however, obtain superior outcomes by sacrificing flexibility--by not making their choices after each instance of misbehavior, but instead adopting a rule that results in automatic punishment after each case of misbehavior. ${ }^{9}$ The Fed could similarly obtain superior outcomes by surrendering flexibility in favor of a rule of the type described above. To do so would not only result in improved economic performance, but would also represent genuine policy behavior--as opposed to case-by-case attempts to optimize--of the type that central bank independence is intended to produce. Thus, despite the political pressures described by Kane (1982) and others, the Fed should have a powerful motive to adopt a policy rule: if choices are to be made on a case-by-case basis, there is no reason why they should be made by an independent agency instead of the current administration. 


\section{REFERENCES}

Barro, Robert J., and Gordon, David B., "A Positive Theory of Monetary Policy in a Natural-Rate Model," Journal of Political Economy, August 1983, 91, 589-610.

Brunner, Karl, and Meltzer, Allan H., "Strategies and Tactics for Monetary Control," Carnegie-Rochester Conference Series on Public Policy, Vol. 18, ed. by K. Brunner and A. H. Meltzer. Amsterdam: North Holland, 1983.

Friedman, Benjamin M., "Targets, Instruments, and Indicators of Monetary Policy," Journal of Monetary Economics, October $1975,1,443-473$.

Friedman, Milton, A Program for Monetary Stability. New York: Fordham University Press, 1960.

Kane, Edward J., "Selecting Monetary Targets in a Changing Financial Environment," Monetary Policy Issues in the 1980s, Federal Reserve Bank of Kansas City, 1982.

Kydland, Finn E., and Prescott, Edward C., "Rules Rather than Discretion: The Inconsistency of Optimal Plans," Journal of Political Economy, June 1977, 85, 473-491.

McCallum, Bennett T., "Monetarist Principles and the Money Stock Growth Rule," American Economic Review Papers and Proceedings," May $1981,71,134-138$.

McCallum, Bennett T., and Hoehn, James G., "Instrument Choice for Money Stock Control with Contemporaneous and Lagged Reserve

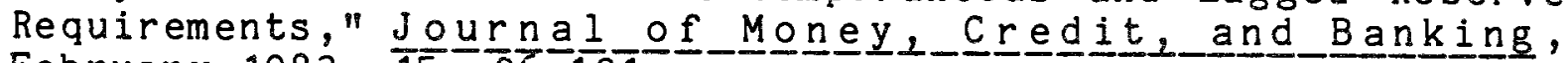
February 1983, 15, $96-101$.

U.S. Congress, Joint Economic Committee, Monetarism and the Federal Reserve's Conduct of Monetary Policy. U.S. Government Printing of $f$ ice, 1982 . 
FOOTNOTES

Professor of Economics, Carnegie-Mellon University; Research Associate, National Bureau of Economic Research; and Adviser, Federal Reserve Bank of Richmond. I am indebted to Marvin Goodfriend and Allan Meltzer for helpful suggestions and to the National Science Foundation (SES 82-08151) for financial support.

1. This is suggested by the analytical results in McCallum and Hoehn (1983) as well as the discussion in Brunner and Meltzer (1983) and elsewhere.

2. From December, 1979, through June 1982, the average M1 growth rate was $6.1 \%$. During 1970-79 the figure was $6.6 \%$; for 1960-79 it was 5.2\%. (Data from Economic Report of the President, February 1983).

3. See, for example, contributions by Volcker, M. Friedman, and Meltzer in the Joint Economic Committee's. Monetarism and the Federal Reserve's Conduct of Monetary Policy (1982).

4. These hypotheses are discussed in McCallum (1981). That neither the second or third of the four cited facts is inconsistent with monetarist principles should not need to be argued. The first fact would be inconsistent with the "Ricardian" brand of monetarism if it were established that the high interest rates of 1980-81 resulted from unmonetized deficits, but such is only one hypothesis. Also, less extreme forms of monetarism are more typical. And as for the 
fourth fact, a change in velocity does not imply a shift in money demand behavior--a sharp drop in interest rates (as in i982) should induce a velocity decline according to most theories. Furthermore, evidence of behavioral shifts taken from studies of conventional money demand functions is unsatisfactory because estimates of the usual (Goldfeld) specification are implausible, implying as they do that many quarters are needed for portfolio adjustments that can be effected almost instantaneously with negligible cost.

5. Furthermore, it would appear that extremely good substitutes for bank deposits can be developed by intermediaries not subject to any given set of regulations.

6. The importance of conrollability and the absence of ambiguity play crucial roles in Milton Friedman's argument for a rule expressed in terms of the money stock, rather than the price level (1960, pp. 86-89). Emphasis on the monetary base has long been recommended by Brunner and Meltzer. Another possible instrument is total reserves.

7. If the economy is in fact Keynesian in nature, these countercyclical effects would be likely to be helpful. If it is in fact purely classical, they should be neither helpful nor harmful.

8. This analogy was suggested to me by Stanley Fischer. The argument that is is supposed to elucidate was originally developed by Kydland and Prescott (1977) and was usefully elaborated by Barro and Gordon (1983). The reader is referred to these papers for a more formal analysis, 
including a more precise specification of the assumed nature of the economy. The argument abstracts from cyclical fluctuations only for simplicity.

9. This is only a hypothetical possibility, of course; I do not claim to know of any actual cases. 